\title{
CIRCADIAN RHYTHMS AND THEIR SIGNIFICANCE TO THE ANAESTHETIST: A REVIEW
}

\author{
Mary E. HunTER, M.D., C.M., F.R.C.P.(c)*
}

THE TERM "circadian" is a relatively new one, having been introduced into general use by Halberg1 only about ten years ago. Basically it is used in reference to our built-in biological "clock," and implies a cycle "about 24 hours" in duration. Use of "circadian" avoids the ambiguity of the term "diurnal," or confusion resulting from the many cyclical functions imposed on us by certain external factors such as habit and environment. "Zeitgeber," a term introduced by Aschoff, ${ }^{2}$ is used to refer to the specific factor in the environment that "sets" the phase of any such biological rhythm.

Because most men are subject to a regular rhythmic cycle of about 24 hours' duration involving rest and activity, meals and fasting, light and darkness, it is important to understand and evaluate the significance of these patterns in the metabolic and biological behaviour we, as anaesthetists, observe and assess as we manage the ill patient, particularly as it may be over a protracted period of respiratory failure or intensive care.

Throughout our training as physicians we were made aware of Bernard's concept of "la fixeté du milieu interieur" and "homeostasis"; however, today we must imagine a milieu that is not only constantly changing, but one that is subject to many cyclical influences, both exogenous and endogenous; of these the "circadian rhythm" is felt to be of fundamental biological importance. ${ }^{3}$ Recently many studies have been made to determine how exactly these basic biological rhythms may influence our emotional and physiological rhythms and behaviour, sleep patterns, postoperative mortality statistics, toxic doses of drugs and chemical agents, and certain basic biochemical "normal" laboratory values.

This brief review is intended only to be a superficial introduction into a most complex but fascinating aspect of human physiological behaviour. Perhaps it may stimulate some interest in the basic biological problems involved when we ourselves get caught up in intercontinental travel and experience the "jet-lag," or when we deprive our very ill patients of the normal day-night, light-dark sequences, as in long-term postoperative recovery cases when long periods of constant care are imposed "round the clock."

A brief summary will be presented of the experimental evidence available to elucidate the existence and nature of this phenomenon. Large numbers of healthy subjects for study have been found in night and shift workers, space flight programmers, Arctic dwellers, modern flight crews, cave and mine workers.

\section{DEvelopment}

In man, circadian rhythms are not present at birth, but will develop during the first year of life, ${ }^{4}$ presumably in response to exposure to the light-dark se-

-Department of Anaesthesia, Toronto General Hospital, Toronto, Ontario. 
quence. Thus, a slow nocturnal pulse rate develops around six weeks of age, and about the same time also, a day-night periodicity in body temperature and uneven distributions between sleeping and waking times, feeding patterns, and urine flow.

The circadian "clock" (this may be placed tentatively in the region of the hypothalamus ) probably develops ${ }^{5}$ as a result of exposure to circadian periodicity in the environment, and is continually being influenced by a variety of external and internal factors. Maturation may well be due to a developing ability to respond to these Zeitgeber.

In man, once it is fully developed, it will survive, despite a constant unvarying external environment imposed on it. In mice, reared in a constant light level, a circadian rhythm has persisted for several generations. ${ }^{6}$

\section{SLeep Pattern}

Anyone who has ever spent a night up for any reason is aware that sleepiness and wakefulness have a circadian rhythm. Great individuality occurs in this; certain subjects can adjust their cycle easily to different phasing, others find it more difficult. ${ }^{7}$ This rhythm may result from changes in body temperature or adrenal activity or it may arise in the central nervous system, probably the cortex in the adult. It is clearly endogenous, and may easily be detected in electroencephalograms ${ }^{8}$ and in psychomotor performance and other skill testing. ${ }^{9}$

\section{Temperature}

Good evidence exists ${ }^{10}$ that there is an endogenous rhythm in body temperature, one to which the hypothalamus responds; but it is one of the most readily adaptable of biological rhythms, taking only from three days to three weeks to change in night workers in hospitals, or in Arctic dwellers. Social surroundings are probably the effective Zeitgeber in man. ${ }^{11}$ The amplitude of this cycle is as large in people confined to bed and in the paralysed as it is in a normally active man, and it is also independent of climatic conditions. The cause of the temperature cycle probably lies in the mechanisms regulating the balance between heat production and heat loss. ${ }^{12}$

\section{RESPIRATION}

Circadian variations in breathing may well be due to this sleepiness-wakefulness cycle, implying a circadian periodicity in the neural drive to the respiratory centre. At night, a slight depression of respiration with a consequent alveolar $\mathrm{PCO}_{2}$ elevation is seen whether the subject sleeps or not. ${ }^{13,14}$ Healthy men will show a sharp reduction in vital capacity soon after midnight, probably due to an increased volume of blood in the pulmonary vessels. Even airway resistance varies circadianly to a significant degree, although no investigation into the cause is known to this author. 


\section{Cardiovascular System}

A diumal periodicity has been recorded in a wide variety of circulatory parameters, e.g. pulse rate, blood pressure, cardiac output, venous pressure, and circulating blood volume, but it is not known if any of these have an independent endogenous origin, as normally many of the circulatory variables are interrelated.

\section{Adrenal Cortex}

Many workers have measured the plasma corticosteroids (particularly cortisol) in order to determine the origins of the circadian rhythm but conclusions have varied. Normally observed values show a "peak" time just before or around the time of awakening. ${ }^{15}$ This increase in morning secretion may be the cause, however, rather than the result of arousal, since it usually occurs in the latest hours of sleep. ${ }^{12}$

A normal pattern has been found in totally blind subjects, nurses, and night watchmen, ${ }^{16}$ but it is absent in disease states associated with abnormal patterns of sleep or consciousness, e.g. delirium and coma. ${ }^{17}$ Plasma corticosteroid rhythm is also absent in Cushing's disease, ${ }^{18}$ in which pituitary production of ACTH may be deranged.

5-Hydroxy tryptamine (serotonin), which is probably a central mediator in the sleep mechanism, has also been described as having a circadian rhythm in laboratory mice, hamsters, and rats. ${ }^{19}$

Perhaps the following hypothesis is tenable now. Somewhere in the area of the cortical-reticular substance (responsible for the conscious state) there is a region which receives a variety of circadian periodic influences, and it is this excitation which is transmitted to the hypothalamus and median eminence and results in release of various levels of corticotrophin-releasing factor (CRF) and $\mathrm{ACTH}$, and thus cortisol production, release, and excretion, and its subsequent detection and measurement in the plasma and urine. (Though aldosterone is likely of equal importance it is not as easy to measure.)

\section{KIDNEY}

We know the ancients were aware of a diminished urine flow at night, but this was always thought due to the decreased fluid intake during sleep. In $1890 \mathrm{Lähr}$ demonstrated that if he stayed recumbent and kept a constant fluid intake over 24 hours his urine flow was still least during the eight hours of sleep. ${ }^{20}$ Since then, many authors have agreed that a nocturnal oliguria persists with an even 24-hour fluid intake.

Posterior pituitary liberation rates of antidiuretic hormone (ADH) and the total solute exaction doubtless produce many circadian variations in urine flow rate. Several observers have advanced the view that light-dark cycles may be of 'particular importance in this control. ${ }^{21}$ It is not understood, though, whether the renal circadian ${ }^{22}$ rhythm is a passive result of waking and sleeping, or whether 
both result from the influence of the endogenous clock - here perhaps a more important factor than habit and activity. ${ }^{23}$ Ultimately the aim will be to specify the nature of these various influences, but one may now presume them to be of a chemical and not of a nervous origin since the transplanted human kidney will show the usual circadian rhythm. ${ }^{24}$

The rhythmic excretion of electrolytes ( $\mathrm{Na}, \mathrm{Cl}, \mathrm{K}$ - all three varying simultaneously) is now generally conceded to be due to rhythmic adrenal activity on the evidence of cases of adrenal deficiency and pharmacological interference with adrenal function in patients receiving sustained higher doses of corticosteroids; ${ }^{18}$ i.e. it is both exogenous and endogenous. Constant artificial ventilation for some weeks in patients with respiratory paralysis will often abolish these normal $\mathrm{Na}$, $\mathrm{Cl}$, and $\mathrm{K}$ excretory rhythms; perhaps because the kidney requires some periodic stimulus such as a cyclical change in carbon dioxide tension or adrenal steroids to reinforce its own rhythm. ${ }^{25}$

\section{BLOOD}

The eosinophil count has long been observed to fall during the first waking hours. A similar fall in the lymphocytes is seen. This phenomenon is constant enough to be used as a guide to measure the occurrence of a circadian rhythm in an otherwise constant environment. There is much evidence to link this eosinopenia to the rhythm of adrenocortical activity, as it is absent in Addison's disease, after bilateral adrenalectomy, and in hypopituitarism. ${ }^{26}$ Light also appears to be an important Zeitgeber, for some authors have found that the eosinopenia occurs earlier in the summer months and is diminished in the blind. ${ }^{27}$

Haematocrit, haemoglobin, red blood cell size and numbers, sedimentation rate, plasma proteins, and amino acids have been observed to have a circadian periodicity. ${ }^{28}$ Some of this is undoubtedly due to habit and to the redistribution of body fluids from chinges in posture and activity, but one author who has subjected his large volume of data to close analysis has observed that not all of these changes can be interpreted in this way. ${ }^{29}$

\section{Pathology}

When a physiological change can be altered by circadian rhythm we can understand how this may contribute to the pathological state. Cerebral haemorrhage, pulmonary oedema, and cardiac asthma have long been known to have a nocturnal incidence; and haemoptysis has an unequal incidence, with peaks between 0600 and 0900 and between 1800 and 2100 hours, which have been ascribed to periods of rapid change in the blood content of the lungs, as assessed by changes in vital capacity. ${ }^{30}$

A similar physiological rhythm is probably responsible for the peak incidence of death in the small morning hours, ${ }^{10}$ and clearly certain psychoses have been long observed to have a circadian periodicity. The mental disturbances occurring in patients kept under a constant light environment, under constant care, and not 
allowed circumscribed periods of dark and rest may be partly due to the disturbance of this rhythm. ${ }^{31}$

Investigation into lethal doses of drugs and toxins cannot be carried out in humans, of course, but experiments on mice have shown unexpectedly large and quite reproducible circadian variations in susceptibility to drugs or bacterial toxins, the identical dose producing a mortality ranging from over 80 per cent to under 20 per cent depending on the time of day it is administered. ${ }^{10,82}$

When attempting to make a diagnosis of the "normal," laboratory values must be observed with a greater appreciation and awareness of the circadian rhythm, as in assessing urine volumes, plasma phosphate excretions, or plasma 17-hydroxycorticosteroid concentrations.

Patients with pulmonary tuberculosis frequently show an abnormal circadian rhythm of vital capacity, as do some patients with asthma and heart failure. Patients with acute glomerulonephritis ${ }^{33}$ can show a very large circadian variation in blood pressure (which subsides during recovery) so that blood pressure estimations should always be made at the same time of day for significance during the course of the disease. In acute glaucoma, the daily range of intraocular pressures is usually far wider than in the healthy eye.

\section{Summary and Conclusions}

Many functions show a circadian rhythm, and it has recently been shown that this natural rhythm is of great practical importance, especially if we attempt to understand why mortality should vary so greatly at different times of the day from various causes and why we are aware of certain phenomena occurring when we are deprived of a natural periodicity in our day. There is certainly a circadian biological "clock," and it may with fair certainty be placed in the region of the hypothalamus. There is no real evidence that more than one such "clock" exists, but it is quite within the realm of possibility that endogenous rhythms may occur at many different levels of physiological organization. Some of the circadian rhythmicity must be merely impressed on the receptive region by habit, sensory deprivation, environment and social contact, and the function of light and darkness; other circadian influences - Zeitgeber - must only adjust the timing, as circadian rhythm occurs quite naturally in animals that have never been exposed to any known rhythm. It is the hypothalamic region that apparently triggers these rhythms. How this region may be stimulated by a signal from the eye, or from the region of the eye, is unknown; but it is certainly the hypothalamus which thus activates the pituitary, which in turn regulates the adrenal cortex, the thyroid, the reproductive organs, and so the entire endocrine and metabolic systems which keep us all "turning over" in a circadian rhythm. Thus, when we come to understand how outside pathological and even iatrogenic influences can disrupt this intrinsic normal biological pattern (which may or may not be measured in quantitative terms) we should no longer be surprised to find basic dislocations occurring in the integrity of the organism, and we should be able to predict how they may alter the patient's progress. 


\section{REFERENCES}

1. Halberg, F. Physiologic 24-hour Periodicity: General and Procedural Considerations with Reference to the Adrenal Cycle. Ztschr. Vitamin- Hormon- u. Fermentforsch. 10: 225 (1969).

2. Aschoff, J. Zeitgeber der tierischen Tagesperiodik. Naturwissenschaften. 3: 49 (1954).

3. Halberg, F. Some Physiological and Clinical Aspects of 24-hour Periodicity. J. Lancet. 73: 20 (1953).

4. Hellarügce, T. The Development of Circadian Rhythms in Infants. Cold Spring Harbor Symp. Quant. Biol. 25: 311 (1960).

5. Lobban, M. C. The Entrainment of Circadian Rhythms in Man, Cold Spring Harbor Symp. Quant. Biol. 25: 325 (1960).

6. Aschoff, J. Tierische Periodik unter dem Einfluss von Zeitgebern. J. Tierpsychol. 15: 1 (1958).

7. KLeitman, N. Sleep and Wakefulness. 2nd ed., University of Chicago Press (1963), pp. 134-84.

8. Frank, G.; Harner, R.; Matrhews, J.; Johnson, E.; \& Halberc, F. Circadian Periodicity and the Human Electroencephalogram. Electroencephalog. Clin. Neurophysiol. 13: 822 (1961).

9. Freeman, G. L. \& Hovland, C. I. Diumal Variations in Performance and Related Physiological Processes. Psychol. Bull. 31: 777 (1934).

10. Halberc, F. Temporal Coordination of Physiologic Function. Cold Spring Harbor Symp. Quant. Biol. 25: 289 (1960).

11. Polimantr, $O$. Sopra la possibilità di una inversione della temperatura giornaliera nelliuomo. Ztschr, allg. Physiol. 16: 506 (1914).

12. Halberg, F.; Halberg, E.; Barnum, C. P.; \& Bittner, J. J. Physiologic 24-hour Periodicity in Human Beings and Mice, the Lighting Regimen, and Daily Routine. In: Photoperiodism and Related Phenomena in Plants and Animals. Washington, D.C.: Am. Assoc. Advan. Sci. Publ. 55 (1959).

13. BüLow, K. Respiration and Wakefulness in Man. Acta Physiol. Scandinav. 59, suppl. 209: 1 (1963).

14. Mruss, J. N. Changes in Alveolar Carbon Dioxide Tension by Night and during Sleep. J. Physiol. 122: 66 (1953)

15. Bafter, F. C.; Delea, C. S.; \& Halberg, F. A Map of Blood and Urinary Changes Related to Circadian Variations in Adrenal Cortical Function in Normal Subjects. Ann. New York Acad. Sc. 98: 969 (1962).

16. Migeon, C. J.; Tyler, F. H.; Mahoney, J. P.; Florentin, A. A.; Castle, H.; Bliss, E. L.; \& SAmuels, L. T. The Diurnal Variation of Plasma Levels and Urinary Excretion of 17-Hydroxy-corticosteroids in Normal Subjects, Night Workers and Blind Subjects. J. Clin. Endocrinol. Metab. 16: 622 (1956).

17. Eik-Nes, K. \& Clark, L. D. Diurnal Variation of Plasma 17-Hydroxy-corticosteroids in Subjects Suffering from Severe Brain Damage. J. Clin. Endocrinol. Metab. 18: 764 (1958).

18. Doe, R. P.; Vennes, J. A.; \& Flink, E. B. Diurnal Variation of 17-Hydroxy-corticosteroids, Sodium, Potassium, Magnesium and Creatinine in Normal Subjects and Cushing's Syndrome. J. Clin. Endocrinol. Metab. 20: 253 (1960).

19. Quay, W. B. Differences in Circadian Rhythm in 5-Hydroxy-tryptamine According to Brain Region. Am. J. Physiol. 215: 1448 (1968).

20. LäHR, H. Versuche über den Einfluss des Schlafes auf den Stoffwechsel. Allg. Ztg. Psychiat. 46: 286 (1889).

21. Lobban, M. C. Dissociation in Human Rhythmic Function. In: Circadian Clocks. J. Aschoff, ed. Amsterdam: North Holland Publishing Co. (1965), p. 219.

22. Mills, J. N. Circadian Rhythms during and after Three Months in Solitude Underground. J. Physiol. 174: 217 (1964).

23. Sharp, G. W. G. The Effect of Light on the Morning Increase in Urine Flow. J. Endocrinol. 21: $219(1960)$.

24. GunN, H. E.; Unger, A. L.; Hume, D. M.; \& Schllling, J. A. Human Renal Transplantation: An Investigation of the Functional Status of the Denervated Kidney after Successful Homotransplantation in Identical Twins. J. Lab. Clin. Med. 56: 1 (1960).

25. Marshall, J. Alterations in the Diurnal Excretion of Electrolytes during Intermittent Positive Pressure Respiration. Brit. M. J. ii: 85 (1959). 
26. Halberc, F.; Visscher, M. B.; Flink, E. B.; Berc, K.; \& Bock, F. Diurnal Rhythmic Changes in Blood Eosinophil Levels in Health and in Certain Diseases. J. Lancet. 71: 312 (1951).

27. Doe, R. P.; Flink, E. B.; \& Goodsell, M. G. Relationship of Diumal Variation in 17Hydroxycorticosteroid Levels in Blood and Urine to Eosinophils and Electrolyte Excretion. J. Clin. Endocrinol. Metab. 16: 196 (1956).

28. Feigin, R. D.; Klainer, A. S.; \& Bersel, W. R. Circadian Periodicity of Blood AminoAcids in Adult Man. Nature. 215: 512 (1967).

29. Renbourn, E. T. Variation, Diurnal and over Longer Periods of Time, in Blood Haemoglobin, Haematocrit, Plasma Protein, Erythrocyte Sedimentation Rate, and Blood Chloride. J. Hyg. 45: 455 (1947).

30. Dissman, E. Lungenblutung und 24-Stunden-Rhythmus. Acta tuberc. Scandinav. 24: 277 (1950).

31. Parker, D. L. \& Hodge, J. R. Delirium in a Coronary Care Unit. J.A.M.A. 201: 702 (1967)

32. Schering, L. E.: Vedral, D. F.; \& Pauly, J. E. A Circadian Susceptibility Rhythm in Rats to Pentobarbital Sodium. Anat. Record. 160:741 (1968).

33. MenzeL, W. L. Der 24-Stunden-Rhythmus des Menschlichen Blutkreislaufes. Ergebn. inn. Med. u. Kinderh. 61: 1 (1942). 